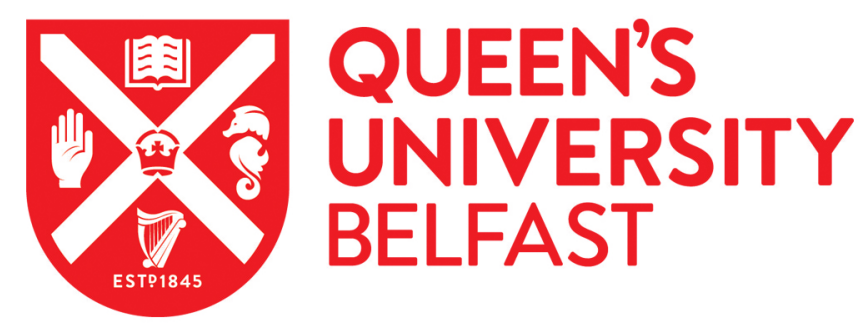

\title{
Un caso de ocultación de autoría en la literatura costumbrista durante el reinado de Carlos IV: la serie en torno a las ferias de Madrid (1791- 1796)
}

Harty, C. (2020). Un caso de ocultación de autoría en la literatura costumbrista durante el reinado de Carlos IV: la serie en torno a las ferias de Madrid (1791-1796). Cuadernos de Estudios del Siglo XVIII, 30, 707-742. [1]. https://reunido.uniovi.es/index.php/CESXVIII/article/view/15799

Published in:

Cuadernos de Estudios del Siglo XVIII

Document Version:

Publisher's PDF, also known as Version of record

Queen's University Belfast - Research Portal:

Link to publication record in Queen's University Belfast Research Portal

\begin{abstract}
Publisher rights
(C) 2020 The Author.

This work is published in the electronic edition of the journal under a Creative Commons Attribution-NonCommercial-NoDerivs 3.0 Spain license It can be copied, used, disseminated, transmitted and publicly exhibited, provided that: i) the authorship and original source of its publication (magazine, publisher and URL of the work) is cited; ii) are not used for commercial purposes; iii) the existence and specifications of this user license are mentioned.

General rights

Copyright for the publications made accessible via the Queen's University Belfast Research Portal is retained by the author(s) and / or other copyright owners and it is a condition of accessing these publications that users recognise and abide by the legal requirements associated with these rights.
\end{abstract}

Take down policy

The Research Portal is Queen's institutional repository that provides access to Queen's research output. Every effort has been made to ensure that content in the Research Portal does not infringe any person's rights, or applicable UK laws. If you discover content in the Research Portal that you believe breaches copyright or violates any law, please contact openaccess@qub.ac.uk. 


\section{Un caso de ocultación de autoría en la literatura costumbrista durante el reinado de Carlos IV: la serie en torno a las ferias de Madrid (1791-1796)}

A case of hidden authorship in costumbrista literature during the reign of Charles IV: the series on the ferias de Madrid (1791-1796)

Ciaran Harty

Queen's University Belfast 


\section{Resumen}

Este artículo aborda un caso de ocultación de autoría en una serie de obras de carácter costumbrista en torno a las ferias de Madrid publicada entre 1791 y 1796. Mis vagatelas, ó las ferias de Madrid (1791), El tiempo de ferias, ó Jacinto en Madrid (1793) —ambas de autor anónimo-, y El Ropavejero literario, en las ferias de Madrid (1796) de Desiderio Cerdonio, reimpresa en 1834, se anunciaron periódicamente en la prensa madrileña, principalmente en la Gaceta de Madrid y el Diario de Madrid. Estos anuncios nos ofrecen la oportunidad de examinar la publicidad y la comercialización de estas obras dentro del mercado del libro madrileño, y pueden servir como fuentes útiles de identificación autoral. El propósito del presente trabajo es, por lo tanto, ofrecer una aproximación a este corpus de textos, situándolo dentro de la literatura costumbrista que fue surgiendo durante la época de Carlos IV, recurriendo a los anuncios de prensa de las tres obras que componen esta serie a fin de indagar su autoría.

\section{Palabras clave}

Autoría, ferias de Madrid, reinado de Carlos IV, costumbrismo, prensa madrileña, anuncios de libros, mercado del libro.

\section{ABSTRACT}

This article addresses a case of authorship in a series of costumbrista-style works set in the context of the ferias de Madrid published between 1791 and 1796. Mis vagatelas, ó las ferias de Madrid (1791), El tiempo de ferias, ó Jacinto en Madrid (1793) - both published anonymously_, and El Ropavejero literario, en las ferias de Madrid (1796), signed by Desiderio Cerdonio and reissued in 1834, were advertised periodically in the Madrid press, mainly in the Gaceta de Madrid and the Diario de Madrid. These advertisements allow us to get a detailed understanding of the marketing and commercialisation of these works in the Madrid book market and serve as useful tools for explaining their connection. Therefore, the aim of this study is to analyse this textual corpus, situating it in the costumbrista-style literature that emerged during the reign of Charles IV, prior to consulting the advertisements for the three works published in the official and local press in order to determine their authorship.

KEY WoRDS

Authorship, ferias de Madrid, reign of Charles IV, costumbrismo, Madrid periodical press, book announcements, book market.

Recibido: 21 de enero de 2020. Aceptado: 11 de marzo de 2020.

Una versión reducida de este artículo se presentó en las II Jornadas de Investigación de Jóvenes Dieciochistas, celebradas en la Universidad de Oviedo del 2 al 3 de octubre de 2019. 


\section{Introducción}

Entre 1791 y 1796 se publicó una serie de tres obras de carácter costumbrista en torno a las ferias de Madrid. La primera, de autor anónimo y que vio la luz en 1791, se titula Mis vagatelas, ó las ferias de Madrid, mueble de moda, especialmente para las damas y petimetres literatos ${ }^{1}$. Se trata de una obra ambientada en torno a las ferias de Madrid, que ofrece un retrato pintoresco de la sociedad madrileña de finales del siglo XVIII, centrándose en los diferentes tipos sociales madrileños característicos de este período y sus interacciones en los espacios de sociabilidad pública, en particular la Plaza de la Cebada. Dos años más tarde, en 1793, se publicó El tiempo de ferias, ó Jacinto en Madrid ${ }^{2}$, novela didáctica dirigida a los jóvenes, también de autor anónimo. En este texto el narrador adopta un tono moralizante, centrándose en retratar y criticar los modos de vida desmesurados de algunos jóvenes en la Corte. Pocos años después, en 1796, apareció El Ropavejero literario, en las ferias de Madrid ${ }^{3}$, obra firmada por Desiderio Cerdonio, que se reeditaría con ligeras alteraciones décadas más tarde en Barcelona en 1834. Sorprendentemente, los once primeros capítulos del texto de Cerdonio de 1796 reproducen la mayor parte de Mis vagatelas, mientras que los veintidós capítulos restantes son una reproducción de los capítulos centrales de $E l$ tiempo de ferias. Como tendremos ocasión de ver, en la apropiación de estas dos primeras obras por El Ropavejero en sus dos ediciones hay solo cambios mínimos, que se observan en la ortografía, los títulos de los capítulos y los nombres de los personajes.

Algunos estudiosos han indicado la relación entre estas tres obras y comentado ciertos episodios, pero hasta ahora no se ha realizado un estudio particular

1 Anónimo, Mis vagatelas, ó las ferias de Madrid, mueble de moda, especialmente para las damas y petimetres literatos, Madrid, en la Imprenta de González, 1791, 8º 58 págs.

2 Anónimo, El tiempo de ferias, ó Jacinto en Madrid, Madrid, en la Imprenta de Ramón Ruiz, 1793, $8^{\circ}, 128$ págs.

3 Desiderio Cerdonio, El Ropavejero literario, en las ferias de Madrid. Obra tan util como las mas, y tan inocente como pocas. Dala á luz D. Desiderio Cerdonio, Madrid, en la Imprenta de Villalpando, 1796, $8^{\circ}$, [4], 149 págs. 
de esta serie a fin de indagar su autoría ${ }^{4}$. Salvador García Castañeda, por ejemplo, hace unos años señaló brevemente las conexiones que acabamos de apuntar:

Parece que las tres proceden de una misma pluma; Vagatelas, está dedicada a describir las Ferias, Jacinto en Madrid cuenta principalmente la historia de este personaje y apenas habla de las ferias y los once primeros capítulos de El ropavejero literario reproducen los correspondientes a Vagatelas, mientras que desde el capítulo XII hasta el final (XXXVI), corresponden a Jacinto en Madrid, sin más variantes notables que el cambio de título de los capítulos y los nombres de los protagonistas 5 .

En este rápido comentario insertado como nota al pie de página en un artículo suyo, García Castañeda subraya en términos generales la conexión entre las tres obras que componen esta serie, si bien no considera la segunda edición de El Ropavejero, ni aclara la cuestión de la autoría. El objetivo del presente trabajo es, por tanto, ofrecer un análisis completo de este corpus textual, examinando en detalle las coincidencias y divergencias que se observan entre Mis vagatelas, El tiempo de ferias, y las dos ediciones de El Ropavejero, a fin de determinar la autoría de esta serie, atendiendo para ello a los anuncios de los textos publicados en la prensa madrileña de esos años, que pueden tener un valor funcional como mecanismos de identificación autoral. Pero antes de centrarnos en el tema de la autoría, resulta apropiado situar esta serie de obras de carácter costumbrista en un marco histórico-literario.

\section{La literatura costumbrista del reinado de Carlos IV}

El costumbrismo, como género literario, fue desarrollándose durante la segunda mitad del siglo XVIII en correspondencia con los cambios que se daban

4 Véanse Joaquín Álvarez Barrientos, «Novela», en Francisco Aguilar Piñal (ed.), Historia literaria de España en el siglo XVIII, Madrid, Trotta, 1996, págs. 235-283; pág. 263; Juana V́́zQuez MARíN, «Literatura costumbrista», en Francisco Aguilar Piñal (ed.), Historia literaria de España en el siglo XVIII, Madrid, Trotta, 1996, págs. 369-405; pág. 391; Rinaldo FroLDI, «Anticipaciones dieciochescas del costumbrismo romántico», Romanticismo 6, Actas del VI Congreso. El costumbrismo romántico, Roma, Bulzoni, 1996, págs. 163-169; Ana Peñas Ruiz, «Márgenes del costumbrismo en Las Ferias de Madrid (1845) de Neira de Mosquera», en Ana Luisa Baquero Escudero, Fernando Carmona Fernández, Manuel Martínez Arnaldos, y Antonia Martínez PÉrez (eds.), La interconexión genérica en la tradición narrativa, Murcia, Editum, 2011, págs. 159-183; y de la misma autora, Hacia una poética del artículo de costumbres (1830-1850), tesis doctoral defendida en la Universidad de Murcia en 2013, págs. 152-153.

5 Salvador García Castañeda, «Vanitas vanitatis: Las ferias de Madrid», Anales de Literatura Española, 20 (2008), págs. 219-240; pág. 228, nota VIII. 
en la teoría literaria y en la concepción de imitación en la estética artística. A lo largo de la centuria anterior, esta tenía la naturaleza como objeto de representación, es decir, ideas abstractas que no se relacionaban con circunstancias concretas, sino con valores universales y absolutos, reflejando así una sociedad arraigada en la religión. En la segunda mitad del siglo XVIII, durante un acelerado período de reforma social y política, tenía lugar un cambio en la imitación artística que abandonaba la naturaleza para hacer a la sociedad el objeto de observación, representándola en diversos géneros artísticos, como la literatura, el teatro y las artes plásticas. José Escobar, en uno de sus numerosos trabajos sobre el costumbrismo, aseveró que esta nueva estética:

Corresponde, entre los siglos XVIII y XIX, a una nueva representación ideológica de la realidad que implica una concepción moderna de la literatura, entendida como forma mimética de lo local y circunstancial mediante la observación minuciosa de rasgos y detalles de ambiente y de comportamiento colectivo diferenciadores de una fisonomía social particularizada y en analogía con la verdad histórica ${ }^{6}$.

Dicho de otro modo, lo general y universal se vieron reemplazados por lo local y temporalmente delimitado que, al decir de Escobar, se hicieron el objecto de la «mímesis costumbrista». Este nuevo modelo estético se asentó en Inglaterra a principios del siglo XVIII, donde fue cultivado por los periodistas británicos Addison y Steele en The Spectator (1711-1712), periódico que tenía a la sociedad británica como objeto de imitación. Años después, durante las últimas décadas del Siglo de la Ilustración, el escritor de moeurs francés LouisSébastien Mercier hizo de la sociedad de la que formaba parte su materia de representación literaria. Como indicó Escobar, en su Tableau de Paris del año 1781, Mercier anunció que iba a «contempler [...] l'assemblage de toutes ces petites coutumes du jour ou de la veille, qui font des loix particulaires; mais qui sont en perpétuelle contradiction avec les loix générales ${ }^{7}$.» Por lo tanto, esta nueva estética artística era transnacional, paneuropea, y no, como ya ha descartado Álvarez Barrientos, de raigambre castiza. Aunque ciertos escritores españoles del período barroco centraron sus obras en la observación de las

6 José EscoBAR, «La mímesis costumbrista», http://www.cervantesvirtual.com/obra-visor/la-mmesiscostumbrista-0/html/0070de7c-82b2-11df-acc7-002185ce6064_4.html\#I_0_, pág. 2. Publicado originalmente en Romance Quarterly, 35.3 (1988), págs. 261-270.

7 José Escobar, «Costumbrismo y novela: el costumbrismo como materia novelable en el siglo XVIII», http://www.cervantesvirtual.com/obra-visor/costumbrismo-y-novela---el-costumbrismo-como-materia-novelable-en-el-siglo-xviii-0/html/0070a0d8-82b2-11df-acc7-002185ce6064 5.html, pág. 3. Publicado originalmente en Ínsula, 546 (1992), págs. 17-19. 
costumbres, como Juan de Zabaleta en su Día de fiesta por la mañana (1654) y Día de fiesta por la tarde (1659), no se debería calificarlos de antecedentes del costumbrismo que surgía a finales del XVIII y que se consolidará como género literario durante los años treinta del XIX, sobre todo con Larra y Mesonero Romanos, principalmente porque la función de esta nueva literatura costumbrista no correspondía a la de la literatura del Seiscientos. En palabras de Álvarez Barrientos:

Los escritores del Siglo de Oro considerados costumbristas utilizaron las costumbres para hacer crítica moral y para ofrecer, en el caso español, un modelo de conducta ajustado a los valores de la moral católica ${ }^{8}$.

Incluso en las obras publicadas durante la primera parte del Siglo de la Razón que podríamos considerar como costumbristas, como añade Froldi, «se pretende atacar y condenar sobre todo la novedad [...] y formas de vida consideradas dañinas y degradadoras de un sano comportamiento tradicional estrechamente ligado a la moral católica $[\ldots]^{9}$.» Sin embargo, los escritores costumbristas de la segunda mitad del xviII no promovían valores absolutos y tradicionales, sino que adoptaban la nueva estética artística — desplegada ya en Inglaterra y Francia-, a las circunstancias de su país para centrarse en la observación de la sociedad española, desarrollando una nueva literatura costumbrista de ámbito civil que ofrecía retratos temporalmente demarcados de los ciudadanos en diferentes espacios públicos, como calles, plazas, paseos, mercados, cafés y tertulias, a fin de representar los nuevos modos de vida que podían observarse en la capital española. Por lo tanto, la sociedad civil y laica retratada en esta naciente literatura de costumbres se distinguía totalmente de la sociedad arraigada en valores tradicionales y absolutos que pintaron los escritores del período barroco y de los albores del siglo XVIII.

En España, este nuevo tipo de literatura costumbrista encontró en los periódicos su primer motor de expresión, sobre todo en los de carácter eminentemente reformista como El Pensador (1762-1767), en el cual empezaron a publicarse artículos que mostraban un interés por la capital española y las costumbres de los madrileños. Sus autores ofrecían descripciones de la sociedad madrileña en diferentes espacios y circunstancias, que se imbricaban con

8 Joaquín Álvarez Barrientos, «El costumbrismo, preso en la construcción de la historia literaria nacional. Una propuesta de renovación», en Dolores Thion Soriano-Mollá (coord.), El costumbrismo, nuevas luces, Pau, Presses de l'Université de Pau et des Pays de l'Adour, 2013, págs. 23-40; pág. 26.

9 Rinaldo Froldi, «Anticipaciones dieciochescas del costumbrismo romántico», Romanticismo 6, Actas del vi Congreso. El costumbrismo romántico, Roma, Bulzoni, 1996, págs. 163-170; pág. 163. 
cuadros más centrados en la crítica moral de las costumbres a fin de corregirlas, y en este sentido cabe destacar que el término «moral» asume una nueva connotación. Como escribe Froldi, en esta incipiente prosa costumbrista, «Se quiere modificar el concepto mismo de moral, no ligada a valores metafísicos y absolutos, sino como proyecciones de la conciencia interior del hombre que debe referirse a sí mismo y a lo que tiene a su alrededor ${ }^{10}$.» Los escritores costumbristas de finales del siglo XVIII típicamente hacían uso de la sátira en sus cuadros moralizantes, tomando como objeto de crítica vicios sociales como el lujo y la ociosidad, y representándolos a través de tipos sociales como los petimetres y las petimetras, ofreciendo así retratos de una realidad idealizada de acuerdo al pensamiento ilustrado.

Durante la época de Carlos IV, estos artículos de carácter costumbrista se publicaban ocasionalmente en el Diario de Madrid, periódico cotidiano de cuatro páginas dedicado a la vida social y económica de la capital española, a la vez que iba apareciendo un conjunto de obras cortas de carácter costumbrista, centradas todas ellas en la representación de la sociedad madrileña y la crítica moral de las costumbres de los madrileños. A este grupo pertenecen las tres obras que abordamos en este estudio -Mis vagatelas, El tiempo de ferias y El Ropavejero-, y también otras como El Instruido en la corte y aventuras del estremeño (1789), de Clara Jara de Soto, Visita de las ferias de Madrid (1790), de Eugenio Villalba, y Viage de un curioso por Madrid (1807), de Eugenio de Tapia. Los autores de estos textos fijan su atención en el entorno social madrileño y pintan a los diferentes tipos sociales de esta época en los espacios urbanos emblemáticos de la capital española, como la Plaza Mayor, la Puerta del Sol y el Paseo del Prado, retratando sus interacciones y los nuevos y chocantes modos de vida que se observaban en el Madrid de finales del siglo XVIII, centrándose así en la representación de la realidad cotidiana. En efecto, como expone Peñas Ruiz, un elemento central de esta literatura es la «mirada costumbrista», que:

Se trata de un tipo característico de aproximación y aprehensión estética de la realidad, en la que el escritor [...] toma como centro de interés los usos y costumbres específicos, el carácter y comportamiento de la sociedad o colectividad en general, o de sus integrantes en particular, es decir, del individuo considerado de forma aislada ${ }^{11}$.

10 Froldi, «Anticipaciones dieciochescas», pág. 164.

11 Peñas Ruiz, Hacia una poética del artículo de costumbres (1830-1850), pág. 33. 
Como ya se ha indicado, en esta literatura costumbrista lo circunstancial y temporalmente demarcado constituye la materia de imitación. En las primeras páginas de sus textos, los escritores costumbristas típicamente nos revelan su deseo de deambular por la capital española y contarnos en forma narrativa lo que observan en sus breves paseos, entrando por los diferentes espacios públicos de la ciudad y ofreciendo así una visión panorámica de la sociedad madrileña. Para cumplir con el aspecto temporal de los retratos costumbristas, los escritores los solían enmarcar en circunstancias específicas a la Villa y Corte, utilizando fiestas y diversiones populares como ambientes mediante los que poder centrarse en la pintura de las costumbres locales.

Este es el caso de las tres obras examinadas en nuestro trabajo que, como indican sus títulos, están todas ambientadas durante las ferias de Madrid. En efecto, en la primera obra, Mis vagatelas, el narrador empieza anunciando su intención costumbrista, preguntando a sus lectores: «¿Qué cosa mas propia para divertir y entretener [...] que una pintura de la Feria, mirada de diversos modos, y exâctamente analizada? ¿Qué libro mas de moda y mas propio de este tiempo que el que trata de quanto pasa en él? ${ }^{12}$ » Declara así su deseo de ofrecer una pintura fiel de la sociedad madrileña durante las ferias, centrándose exclusivamente en retratarla tal como está durante estos días de fiesta, «exactamente analizada», como dice, y adoptando así las cualidades fundamentales del escritor costumbrista.

Por lo que respecta al tema de la serie, las ferias de Madrid se inauguraron en el siglo XV y se celebraban dos veces al año durante dos semanas. Conocidas inicialmente como las ferias de San Mateo y de San Miguel, se unieron en el siglo XVIII a fin de celebrarse anualmente en la capital española durante las dos últimas semanas de septiembre, a principios del otoño ${ }^{13}$. Desde su inauguración tenían lugar en diferentes espacios públicos de Madrid, notablemente en la Plaza Mayor, pero a partir de las décadas centrales del siglo XVIII se fueron asociando principalmente con la Plaza de la Cebada ${ }^{14}$. Durante el período de las ferias llegaban a Madrid muchos visitantes de las provincias y viajeros, deseosos todos de conocer la capital española y aprovechar la variada gama de productos baratos que se vendían, principalmente en la Plaza de la Cebada, pero también en otras calles y lugares aledaños de Madrid. Estos productos incluían libros, muebles usados, enseres domésticos como ollas y escobas, además de juguetes para niños — la mayoría de ellos importados de Alemania— ${ }^{15}$, que se

12 Anónimo, Mis vagatelas, págs. 3-4.

13 García Castañeda, «Vanitas vanitatis», pág. 219.

14 García Castañeda, «Vanitas vanitatis», pág. 219.

15 Charles Kany, Life and Manners in Madrid, 1750-1800, Berkeley, University of California Press, 1932, págs. 112-119. 
vendían en diversas tiendecillas conocidas por el público como covachuelas, notablemente las situadas bajo las gradas de San Felipe el Real ${ }^{16}$.

Desde sus comienzos en el siglo Xv, las ferias llamaron la atención de no pocos escritores, poetas, dramaturgos, artistas y viajeros ${ }^{17}$ cuyas obras, como apunta García Castañeda, «revelan curiosos aspectos de la sociedad madrileña del tiempo, sus usos y costumbres, sus tipos y escenas y, muy especialmente, las reflexiones moralizadoras de sus autores ${ }^{18}$.» En estas obras teatrales y textos en prosa de carácter costumbrista centrados en las ferias se comentaban algunos de los peligros de la Villa y Corte, mostrando a sus lectores que numerosos españoles adinerados se arruinaban con los lujos excesivos que podían adquirirse durante todo el año, pero más específicamente durante el tiempo de las ferias en las calles más eminentemente comerciales de Madrid, en particular la calle Mayor, subrayando también el dudoso comportamiento de nuevos tipos sociales como los petimetres y las petimetras. Entre las representaciones artísticas en las que figuran las ferias de Madrid, destaca un abanico de autor anónimo fabricado alrededor de 1760, en cuyo país se ha pintado una escena típica de las ferias en la que se observan:

Varios cacharreros con cazuelas, cuencos, jarras, sartenes y calderas extendidas en el suelo; vendedoras de platos y vajillas de loza, aguadores con viñetas que salen de sus bocas diciendo «Agua»; cuatro tiendas enfiladas donde se exponen paños textiles, y varios vendedores de barreños y objetos de madera o barro ${ }^{19}$.

Asimismo, el óleo de Manuel de la Cruz titulado La feria de Madrid en la Plaza de la Cebada, pintado entre 1770 y 1780, ilumina la dinámica actividad de las ferias y presenta la Plaza de la Cebada como el núcleo comercial y social de esta fiesta anual ${ }^{20}$; por otro lado, el cartón de Goya La feria de Madrid del año 1779 ofrece una representación visual de cómo los vendedores presionaban a los paseantes para que comprasen sus productos ${ }^{21}$. Por lo que respecta a las

16 Para más información sobre las covachuelas de San Felipe, véanse Gabriel Sánchez EsPinosa, «Los puestos de libros de las gradas de San Felipe de Madrid en el siglo XviII», Goya, 335 (2011), págs. 142-155.

17 Véanse, por ejemplo, los diferentes textos citados por GARCía CASTAÑEDA en «Vanitas vanitatis», y también los que comenta José Simón Díaz en «Las ferias de Madrid en la literatura», Anales del Instituto de Estudios Madrileños, 2 (1967), págs. 249-274.

18 García Castañeda, «Vanitas vanitatis», pág. 221.

19 La feria de Madrid en la Plaza de la Cebada, Patrimonio Nacional, núm. de inventario 10145254, https://www.patrimonionacional.es/colecciones-reales/abanicos/la-feria-de-madrid-en-la-plaza-de-la-cebada.

20 Manuel de la Cruz, La feria de Madrid en la Plaza de la Cebada, Museo del Prado, https://www.museodelprado.es/coleccion/obra-de-arte/la-feria-de-madrid-en-la-plaza-de-la-cebada/d0b93d77-898d-43f691d1-6d6ca16545c2.

${ }^{21}$ Francisco de Goya, La feria de Madrid, Museo del Prado, https://www.museodelprado.es/coleccion/ obra-de-arte/la-feria-de-madrid/021dac59-1e29-4074-902b-bla155e2d637. 
representaciones teatrales de las ferias, un sainete de Ramón de la Cruz del año 1773 titulado Las resultas de las ferias resalta el entusiasmo de un grupo de españoles de provincias llegados a Madrid al darse cuenta de la gran variedad de fruta fresca que se vende en la capital:
Cortinas: ¡Señores, azerolonas
ricas, fresas avellanas
Y melocotones gordos
de Aragón!

Soriano: ¡Vamos, madamas

que se concluye la feria ${ }^{22}$ !

Pero además de los productos de consumo doméstico que se vendían durante las ferias, estas representaban también una provechosa ocasión comercial para autores y libreros, que buscaban animar a los madrileños y a los visitantes de provincias a comprar sus libros. En el siglo XVIII, sobre todo durante sus últimas décadas con el creciente desarrollo de la prensa, los libros de reciente aparición solían anunciarse en los periódicos, notablemente en la oficial Gaceta de Madrid y en el semioficial Diario de Madrid ${ }^{23}$. Los libreros aprovechaban también estos anuncios para intentar saldar las obras de años anteriores que permanecían apiladas en sus estanterías y, como veremos más tarde, las tres obras estudiadas en este trabajo fueron anunciándose en la prensa años después de su primer lanzamiento, en la mayoría de los casos en las semanas inmediatas a las ferias. Estos anuncios, como ya se sabe, representan fuentes de gran utilidad para examinar la vida comercial de determinadas obras en las librerías madrileñas, y procurar así, en el caso de obras anónimas, identificar a sus autores; pero antes de examinarlos para abordar la cuestión de la autoría de esta serie, consideraremos algunas de las prácticas y estrategias autorales utilizadas en la literatura dieciochesca.

22 Ramón DE LA CRuz, Las resultas de las ferias, Madrid, 1773. Su manuscrito autógrafo se conserva en la Biblioteca Histórica Municipal de Madrid, http://www.memoriademadrid.es/buscador.php?accion=VerF icha\&id=119663\&num id=1\&num total=1\#. Publicado por Charles KanY, «Ocho sainetes inéditos de Don Ramón de la Cruz. Editados con notas, según autógrafos existentes en la Biblioteca Municipal de Madrid», University of California Publications in Modern Philology, 13.1 (1925), págs. 1-205; pág. 105, versos 1-6.

${ }_{23}$ Para más información sobre el anuncio de libros en el Diario de Madrid y la Gaceta de Madrid, véanse María José Alonso Seonne, Narrativa de ficción y público en España: los anuncios en la 'Gaceta' y el 'Diario de Madrid' (1808-1819), Madrid, Universitas, 2002; y Joan Cavalllon Giomi, L'édition sous Charles IV. Les annonces de librairie des journaux madrilènes, 1789-1808, Aix-en-Provence, Presses Universitaires de Provence, 2019, págs. 71-82. 
Durante el Siglo de las Luces se fomentaba la publicación y la venta de los libros, sobre todo los de carácter moralizante que buscaban enseñar a los lectores y animarlos a ser útiles a la sociedad. No obstante, el hombre de letras en la España de la Ilustración se enfrentaba a un clima literario hostil que a veces frustraba su trayectoria profesional. En primer lugar, el oficio de autor era precario, puesto que hasta al menos la segunda mitad del siglo, no eran los literatos los principales beneficiarios de la venta de sus obras. Si un escritor quería que su obra viera la luz, dependía de los impresores y libreros que se encargaban, respectivamente, de su tirada y venta. Como consecuencia, en la mayoría de los casos se quedaban ellos la propiedad de la obra y el privilegio de impresión, lo cual hacía que el autor ganara una cantidad inadecuada por su trabajo que no reflejaba de ningún modo las numerosas horas que dedicó a su escritura. Para colmo de males, como explica Álvarez Barrientos, el privilegio solía ser de diez años, y después de expirar, «la propiedad de la obra no tenía por qué volver a su autor, sino que quedaba a disposición de cualquiera que quisiera y pudiera hacerse con ella para explotarla ${ }^{24}$.» Que el privilegio cayera entonces en manos ajenas, una década después de publicar su obra, hacía que el autor continuase siendo explotado y siguiera manteniéndose en la precariedad.

En la segunda mitad del siglo XVIII, durante el reinado de Carlos III, los reformistas borbónicos pusieron esta práctica en tela de juicio y se esforzaron por introducir los derechos de autor, a fin de dar un mayor reconocimiento al valor social y político al oficio de escritor y, en consecuencia, contribuir a su profesionalización. Notablemente, en octubre de 1764 se promulgó una orden que estipuló:

Que los privilegios concedidos a los autores no se extingan por su muerte, sino que pasen a sus herederos, como no sean Comunidades o Manosmuertas; y que a estos herederos se les continúe el privilegio mientras le solicitan, por la atención que merecen aquellos literatos, que después de haber ilustrado su patria, no dejan más patrimonio a sus familias que el honrado caudal de sus propias obras y el estímulo de imitar su buen ejemplo ${ }^{25}$.

$\mathrm{Al}$ implementar esta ley los reformistas dieron un paso adelante para intentar proteger al autor y asegurar que recibiera su merecido reconocimiento.

24 Joaquín Álvarez Barrientos, Los hombres de letras en la España del siglo XVIII. Apóstoles y arribistas, Madrid, Castalia, 2006, pág. 246.

25 Novísima recopilación de las leyes de España, dividida en XII libros, libro VIII, título XVI, ley XXV, 1807. Citado por Álvarez Barrientos en Los hombres de letras, pág. 247. 
Subrayaban cómo las prácticas hasta entonces prevalentes en el mundo literario descreditaban al escritor, que en realidad luchaba por una causa perdida, puesto que mientras él trabajaba como una sola entidad, los libreros e impresores de quienes dependía formaban parte de cofradías auspiciadas por la poderosa industria del libro, lo que les daba una mayor protección. Como escribe Álvarez Barrientos, «Los libreros se agrupaban en el Patronato del Gran Padre de la Iglesia San Jerónimo, y los impresores en la Hermandad de San Juan Bautista, pero los escritores hasta el siglo XIX no tendrán una sociedad que defienda sus derechos ${ }^{26} . »$

Aparte de las dificultades económicas afrontadas por los autores del siglo XVIII, para poder vivir de su pluma también se veían obligados a expresar puntos de vista alineados con los valores encarnados por las instituciones políticas. Dicho de otro modo, para tener éxito como escritor era imprescindible el respaldo gubernamental, y en consecuencia fueron muchos los autores del siglo XVIII cuyas obras manifestaron opiniones que, en ciertos casos, no reflejaban sus verdaderas creencias. Por poner un ejemplo, Checa Beltrán explica cómo Antonio de Capmany modificaba sus consideraciones para alinearlas con las posturas políticas del momento, apuntando que:

Al principio de su carrera, cuando pertenecía al círculo de Olavide, su patriotismo era ilustrado, cosmopolita, defensor de lo moderno y crítico con la anticuada España. Con los años, su entusiasmo reformista decayó notablemente en favor de un nacionalismo cada vez más conservador ${ }^{27}$.

El caso de Capmany demuestra la flexibilidad que exigía entonces la profesión de escritor, lo que representaba un sacrificio que no todos los autores estaban dispuestos a hacer. Además, a los literatos de esta época, se les obligaba a respetar una serie de normas ineludibles para que sus obras pudieran ver la luz. Concretamente, en 1752, por iniciativa del juez de imprentas Juan Curiel, se promulgó una ley que tenía como propósito el permitir la identificación inequívoca de los autores de cualquier obra publicada:

En el principio de cada libro, que así se imprimiere o reimprimiere, se ponga la licencia, tasa o privilegio (si le hubiere), y el nombre del autor y del impresor, y lugar donde se imprimió, con fecha y data verdadera del tiempo de la impresión,

26 Álvarez Barrientos, Los hombres de letras, pág. 250.

27 José CheCA Beltrán, «Apuntes sobre pensamiento literario y estrategias autoriales en el siglo XVIII», Studi Ispanici, 43 (2018), págs. 273-288; pág. 285. 
sin mudarla ni anticiparla, ni suponer nombres, ni hacer otros fraudes ni usar de trazas y cautelas contra lo prevenido de este capítulo ${ }^{28}$.

La entrada en vigor de esta ley permitió que el Consejo de Castilla y la Inquisición — los dos cuerpos de censura en la España del siglo XVIII-, pudieran perseguir a aquellos autores cuyas obras abordaran temas prohibidos, en particular las sátiras políticas y los artículos que criticaban las instituciones religiosas. Como apunta Álvarez Barrientos:

La tendencia en el siglo es identificar a los autores y a sus obras, desde el punto de vista legal, desde el historiográfico, pero también en el orden interno, es decir, para que los implicados supieran quién era el responsable de una sátira o de cualquier ataque anónimo $[\ldots]^{29}$.

A pesar del aparente rigor de esta ley, no siempre se cumplió, y fueron bastantes los autores que decidieron no firmar sus obras, los que se presentaron anónimamente, y también los que utilizaron anagramas y pseudónimos, algunos de ellos de difícil desciframiento, como veremos después. Son varias las razones por las que no pocos autores del siglo XVIII ocultaban su identidad, figurando entre ellas la autoprotección, el miedo a la censura, y también la perpetua amenaza de ser perseguido por la Inquisición, que consideraba el libro como uno de los principales vehículos para la difusión de nuevas ideas alejadas de la mentalidad tradicional, arraigada en valores absolutos. En efecto, Muñoz Sempere comenta que:

The inquisitorial turn against enlightened ideas included the expurgation of works of literary value or scientific utility (and [they] therefore were allowed to be published except for specific passages), as well as the prohibition of books and the whole oeuvre of authors who were considered to be damaging religious unity ${ }^{30}$.

Por lo tanto, la ausencia de la firma y la decisión de presentarse anónimamente se relacionaban primariamente con las circunstancias sociopolíticas

28 Novísima recopilación de las leyes de España, dividida en XII libros, libro VIII, título XVI, ley XXII, 1752. Citado por Philip DeAcon en «El autor esquivo en la cultura española del siglo XVIII: apuntes sobre decoro, estrategias y juegos», Dieciocho, 22.2 (2000), págs. 213-226; pág. 213.

29 Joaquín Álvarez BarRientos, «Ser negro en la República Literaria española del siglo XVIII», en Maud LE Guellec (ed.), El autor oculto en la literatura española. Siglos XIV a XVIII, Madrid, Casa de Velázquez, 2014, págs. 93-106; pág. 96.

30 Daniel Muñoz Sempere, «Inquisition and Enlightenment», en Elizabeth Frankuin Lewis, Mónica Bolufer Peruga and Catherine M. Jaffe (eds.), The Routledge Companion to the Hispanic Enlightenment, London; New York, Routledge, 2020, págs. 355-367; pág. 358. 
del siglo XVIII, pero la ocultación de la identidad también servía como medida a través de la cual el autor podía distanciarse de sus lectores. Como argumenta Deacon, «El carácter esquivo del escritor recuerda al lector que la literatura es un mundo alternativo y que el 'autor' podría ser tan inventado como los personajes que figuran en sus obras ${ }^{31}$.» Además, hay que tener en cuenta, como resalta Álvarez Barrientos, que «La identidad civil, cada vez menos estable, no tiene por qué ser la literaria, y ésta puede llegar a ser varia y divisible, ya se trate de un seudónimo, ya de heterónimos y apócrifos, ya incluso de plagios y alónimos, práctica que consiste en adjudicar a otro autor la obra propia ${ }^{32}$.» Así, ocultar la identidad utilizando estas estrategias constituía también un recurso de la República Literaria, que permitía que los autores pudieran alejarse de la realidad cotidiana y adoptar una máscara a través de la cual presentar sus puntos de vista de manera satírica o jocosa, sin ser identificados.

Otra práctica del ámbito de las letras era el uso de un escritor oculto, lo que se conocía en el mundillo como un negro, término con que se calificaba a alguien que escribía obras para otro escritor, que ponía luego su firma en la portada de un texto que no había salido de su pluma. Representaba una estrategia controvertida, puesto que ciertos literatos de mentalidad tradicional sostenían que solo los escritores sin talento se asociaban con los negros, utilizándolos como medio poco ortodoxo e injusto para ganar prestigio y penetrar en la República de las Letras. Pero como destaca Álvarez Barrientos, fueron muchos los autores del siglo XVIII que emplearon negros en toda una variada gama de actividades literarias, incluso en el caso de escritores establecidos como el periodista Francisco Mariano Nifo, que «se había convertido en una 'marca' y, como tal, pide las licencias de impresión y autoriza con su nombre las traducciones que publica, que en realidad están hechas por otros ${ }^{33}$.» Así, durante períodos de demanda acelerada ciertos autores bien conocidos recurrían a negros, viéndolos como medio eficaz para gestionar mejor su trabajo y permitirse el seguir aumentando su producción literaria sin agobiarse en exceso.

Como ya se ha indicado, el uso de la firma era algo obligado a fin de permitir a las autoridades la directa identificación del autor de una obra, pero la presencia de un nombre en la portada tenía también una finalidad comercial, dado que los libros de reciente aparición se solían anunciar en la prensa, práctica que tenía una doble función, pues en primer lugar servía para mantener al tanto a los

\footnotetext{
31 Philip DEAcon, «El autor esquivo en la cultura española del siglo XVIII: apuntes sobre decoro, estrategias y juegos», Dieciocho, 22.2 (1999), págs. 213-236; pág. 215.

32 Joaquín Álvarez Barrientos, El crimen de la escritura. Una historia de las falsificaciones literarias españolas, Madrid, Abada, 2014, pág. 30.

33 Álvarez Barrientos, El crimen de la escritura, pág. 42.
} 
lectores del lanzamiento de nuevas obras, publicitando la oferta disponible en los negocios de los diferentes libreros, al tiempo que apoyaba, asimismo, la trayectoria profesional del autor, estableciendo así una biografía literaria. Además, en los periódicos que informaban sobre los libros de reciente aparición - ya en la prensa oficial de carácter nacional, representada por el Mercurio de España, y también en la de carácter más local, como en el semioficial Diario de Madrid-, se publicaban ocasionales reseñas que ofrecían a los lectores breves resúmenes de las obras antes de comprarlas. Como subraya Cavaillon Giomi, la publicidad de los libros representaba:

Une aubaine pour les hommes de Lettres de cette fin de siècle qui virent dans les annonces de librairie un moyen rapide et efficace de voir l'information de leurs écrits diffusée auprès d'un public le plus large possible ${ }^{34}$.

En el caso de un autor bien conocido, la firma permitía que al anunciar su nueva obra, los redactores de los periódicos pudieran relacionarla con otras que habían salido previamente de su pluma, aumentando así las posibilidades de que su nuevo impreso llegara a las manos de un mayor número de lectores. Como señala Deacon, debido a la progresiva profesionalización del autor durante este período, este «tenía que promocionarse y el librero, que vendía sus creaciones, fomentaba las ventas por medio de la identidad de quien había dado origen al texto ${ }^{35}$.»

El uso de la firma también actuaba como mecanismo de protección profesional para los autores que, como ya hemos tenido ocasión de ver, se ganaban la vida con un trabajo precario. Como detalla Álvarez Barrientos, en el siglo XVIII se establecía un conflicto entre el concepto moderno de originalidad, que defendía los derechos intelectuales del autor y su trayectoria profesional, y la idea de que la literatura era patrimonio de todos, «lo que permitía a cualquiera apropiarse del trabajo de otro y glosarlo, traducirlo, añadirle notas o modificaciones que lo hacían suyo, siempre que no se tratara de un texto de un autor clásico cuya obra fuera conocida, estuviera en el canon y se respetara ${ }^{36} . » A$ los aspirantes a escritores se les animaba a que consultasen las obras de autores establecidos, a fin de encontrar modelos de imitación para encarrilar y mejorar sus trabajos, pero a veces esto conducía al plagio y a las falsificaciones literarias, prácticas

34 Cavaillon Giomi, L'édition sous Charles IV, pág. 68.

35 Philip Deacon, «Máscaras culturales: tácticas y juegos autoriales en la España dieciochesca», en Maud Le GuelLec (ed.), El autor oculto en la literatura española. Siglos XIV a XVIII, Madrid, Casa de Velázquez, 2014, págs. 107-124; pág. 108.

36 Álvarez Barrientos, Los hombres de letras, pág. 200. 
ambas cada vez más desprestigiadas con el creciente desarrollo de los derechos autorales. Copiar la obra de otro autor de manera intencionada y cometer así un fraude literario suponía subestimar el valor de su trabajo y hacer caso omiso de los esfuerzos que hizo ese primer autor para escribirlo. Como expone Perromat, «En todas las épocas, ser tachado de «plagiario» (en las ilimitadas maneras en las que esta vaga noción puede encarnarse: copista, ladrón, epígono, imitador...) es quizás la descalificación más severa posible en el Mundo literario $^{37}$.» Todas estas etiquetas se referían a prácticas parecidas que se consideraban crímenes literarios, constituyendo un «léxico de falsificación», al decir de Álvarez Barrientos, para quien la connotación criminal que llevaban tales términos «es fácil de comprender, no solo por lo que las falsificaciones literarias suponen de engaño al lector/consumidor, sino también por las implicaciones que en otros tiempos tuvieron, al servir para legitimar derechos sobre tierras, propiedades y cobros de impuestos $[\ldots]^{38}$.» El acto de falsificar, plagiar, copiar también chocaba con el concepto de originalidad y con los derechos autorales que respaldaba la República literaria, y así, cuando un autor acusaba a otro de plagio demostraba su indignación y su deseo de mancillar la imagen del ladrón y expulsarlo de la República de las Letras. En efecto, añade Álvarez Barrientos que, para el jesuita Daniel Bartoli:

El plagio es ignominioso y pone de manifiesto lo peor de la clase literaria, pues es el resultado de ambición [...] y del deseo de fama, que sólo se logra estudiando, siendo de utilidad pública y con la ayuda de Dios. Para no caer en esos errores, el escritor debe proponerse un buen modelo y seguirlo ${ }^{39}$.

Por todo ello, la firma en la portada de una obra servía para darle autenticidad, además de permitir que los casos de hurtos literarios pudieran identificarse más fácilmente, asegurando así que el plagiario no gozara de los frutos del trabajo de otro autor, y que el autor original recibiera su merecido reconocimiento. Pero como ya se ha indicado, a pesar de la obligación de los autores a firmar sus obras, y las ventajas tanto comerciales como profesionales que ofrecía esta práctica, fueron muchos los hombres de letras que publicaron sus textos de forma anónima, y también los que firmaron sus obras con pseudónimo, como fue el caso de la serie de obras de carácter costumbrista en torno a las ferias de Madrid que

37 Kevin Augustín Perromat, «Plagiarismo: ¿estética o movimiento contemporáneo?», 452º. Revista electrónica de teoría de la literatura y literatura comparada, 5 (2011), págs. 115-127; pág. 117. https://revistes.ub.edu/index.php/452f/issue/view/989.

38 Álvarez Barrientos, El crimen de la escritura, pág. 17.

39 Álvarez Barrientos, Los hombres de letras, pág. 193. 
nos ocupa. A fin de señalar las técnicas utilizadas por el autor de estas obras para intentar ocultar su reproducción, comentaremos a continuación las semejanzas y las diferencias que se observan entre los dos textos originales de 1791 y 1793 y su refundición por El Ropavejero en 1796, así como los cambios que se llevaron a cabo con la segunda edición de esta última obra en 1834, antes de recurrir a los anuncios publicados en la prensa de la época para explicar su conexión.

Continuidades y modificaciones entre Mis vagatelas (1791), El tiempo de ferias (1793), y las dos ediciones de El Ropavejero (1796 y 1834)

La primera obra de esta serie, Mis vagatelas, da comienzo con una «Ligera introduccion» de cuatro páginas en la que el narrador detalla lo que le ha impulsado a escribir ese texto, hablando brevemente también de las ferias. Significativamente, apunta que «la proxîmidad del invierno no[s] exîge nuevos gastos, y algunos escritores suelen no tener mas bienes que sus obras: este es un tiempo acomodado para su venta.» ${ }^{40}$ Subraya así que el período de las ferias en la segunda mitad de septiembre representa una provechosa oportunidad comercial para los escritores que se ganan la vida exclusivamente con la venta de sus obras. Habla también en su introducción de los posibles lectores de su obra. Refiriéndose a la propensión de los españoles de las clases altas a imitar las tendencias marcadas por la capital francesa, cita como ejemplo que: «En algun tiempo hubo en Paris la moda de ser las damas Geómetras; entonces no se oía hablar en los estrados mas que de ángulos, romboydes y trapecios $[\ldots]^{41}$.» A lo que añade, que:

Si se hiciese, pues, la moda de ir á la Feria ó á el Prado con este librito, leerlo en los estrados ó en las sillas que se ponen en la Plazuela de la Cebada, el autor de esta obra lograria seguramente su fin, es decir, una gran ganancia, y nuestras damas y petimetres ser tenidos por sabios y literatos, sin serlo ${ }^{42}$.

Por lo tanto, la referencia que hace el narrador a la inclinación de las mujeres de las clases altas a seguir lo que está de moda en París actúa como modelo para animar a los lectores a comprar su libro, añadiendo satíricamente que permitiría a tipos sociales superficiales como los petimetres el fingir saber mucho.

40 Anónimo, Mis vagatelas, pág. 3.

41 Anónimo, Mis vagatelas, pág. 5.

42 Anónimo, Mis vagatelas, págs. 5-6. 
Estos breves comentarios le sirven como preámbulo a su pintura más detallada de las ferias de Madrid, que constituye el tema de los capítulos centrales.

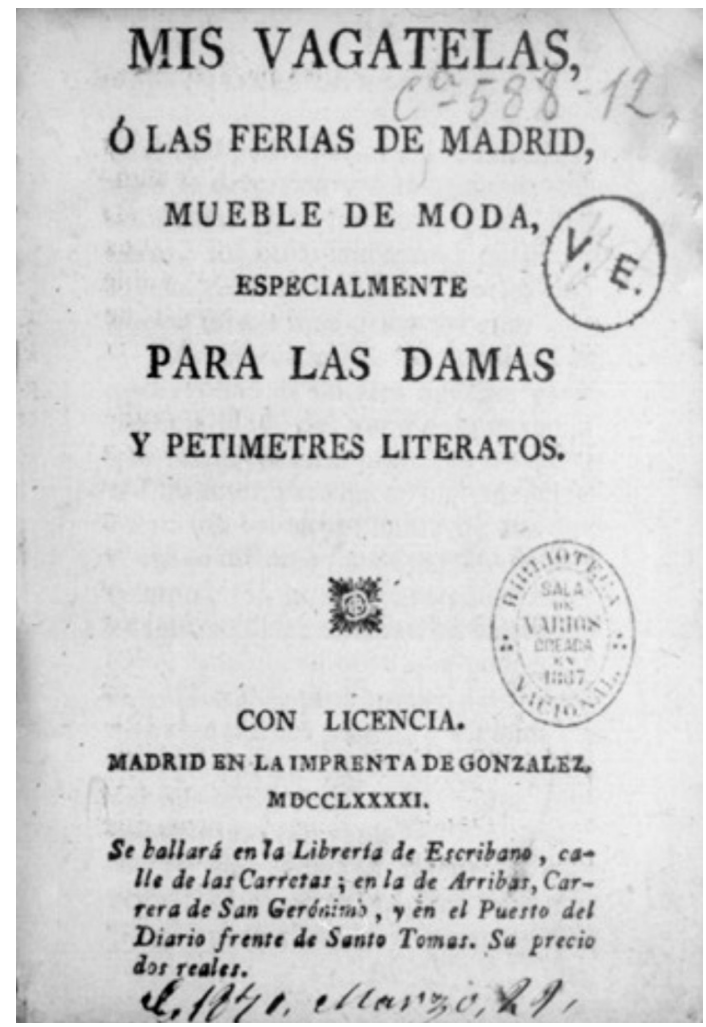

La «Ligera introduccion» a Mis vagatelas no se reprodujo en las primeras páginas de El Ropavejero en 1796, pero el autor incluyó entonces en su lugar una «Advertencia al que leyere». En esta sección introductoria original, también de cuatro páginas, el narrador introduce esta obra supuestamente nueva, apuntando que «por lo menos no se encontrará en ella cosa que pueda corromper las costumbres, ni trastornar la razon ${ }^{43}$, posiblemente para hacer alusión desde las primeras páginas al carácter didáctico que se observará a continuación. Pero aunque las dos secciones introductorias de Mis vagatelas y El Ropavejero son distintas, los once primeros capítulos de El Ropavejero reproducen todos los capítulos de la obra anónima publicada en 1791. A título de ejemplo, en el párrafo que abre el primer capítulo de Mis vagatelas, comenta el narrador:

43 Cerdonio, El Ropavejero, «Advertencia», pág. [2]. 
Nuestra Feria no es como la de Canton en la China, ó la de Dantzick en Europa, ni tampoco como muchas de las mas célebres de la Península: estas Ferias son de comercio, y la de Madrid solo es de vagatelas, de juegos de muchachos, de sillas y esteras; en aquellas se interesan caudales excesivos, y en esta por lo regular solo los bienes de algunos artesanos de mediana fortuna ${ }^{44}$.

Este párrafo se parafrasea inequívocamente en el primer capítulo de $E l$ Ropavejero:

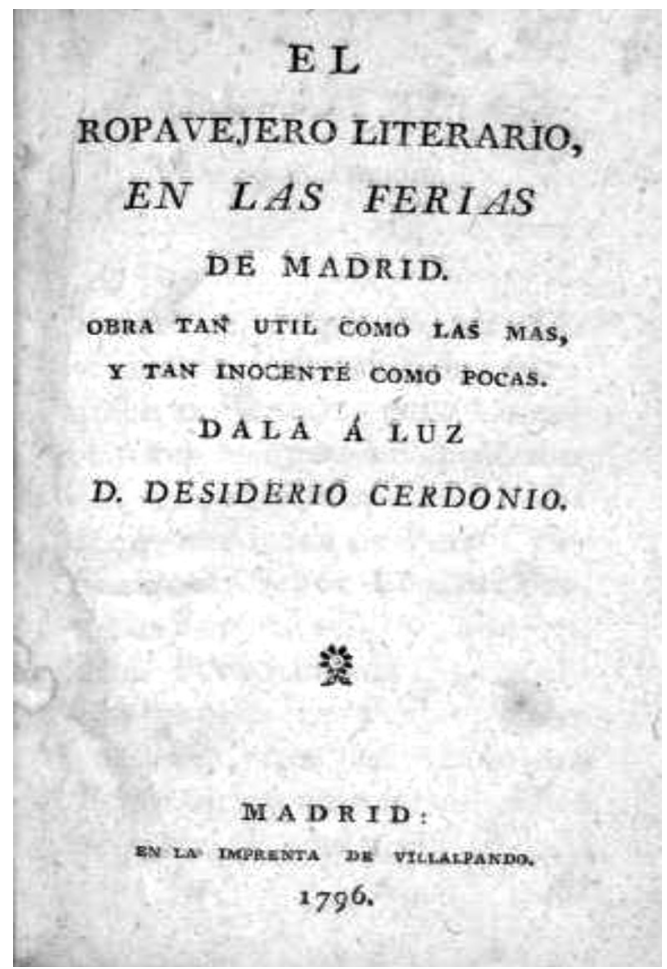

Nuestra Feria no es como muchas de España. Porque estas son de comercio, y la de Madrid solo es de cachivaches, de juegos de muchachos, de sillas y esteras; en aquellas se interesan bastantes caudales, y en ésta por lo regular solo los bienes de algunos artesanos de mediana fortuna ${ }^{45}$.

44 Anónimo, Mis vagatelas, pág. 7.

45 Cerdonio, El Ropavejero, pág. 1. 
Como puede verse, en el párrafo reproducido solo hay cambios mínimos. Llama la atención que la palabra «vagatelas» se sustituya por «cachivaches» en El Ropavejero, lo que señala posiblemente que el autor buscase evitar la repetición de esta voz, que apareció en el título de la obra de 1791, a fin de ocultar su reproducción.

La semejanza entre el texto de Desiderio Cerdonio y Mis vagatelas se hace más clara en el núcleo de este primer capítulo, concretamente cuando el narrador de El Ropavejero habla de los peligros de las ferias. Apunta que «En la casa de Estevan reynaba antes la paz y la quietud, pero la Feria lo ha trastornado todo ${ }^{46}$ », mientras que en la sección correspondiente a Mis vagatelas, podía leerse: «En la casa de Eugenio reynaba antes la paz y la quietud, pero la Feria lo ha trastornado todo ${ }^{47}$.» Se nota aquí la cercanía de los nombres, que empiezan por «E-», y en los diez próximos capítulos de El Ropavejero continúa observándose esta mezcla de paráfrasis, uso de sinónimos, y pequeñas modificaciones en los nombres de los personajes y en los títulos de los capítulos ${ }^{48}$.

Hasta aquí hemos mostrado cómo los once primeros capítulos de El Ropavejero reproducen el texto completo de Mis vagatelas, a excepción del prólogo, que se escribió de nuevo. Los veintidós últimos capítulos del texto firmado por Desiderio Cerdonio reproducen la mayor parte del texto anónimo anterior $E l$ tiempo de ferias. Como ha indicado Peñas Ruiz, en una reseña de esta novela didáctica publicada en el Semanario de Salamanca el 12 de diciembre de 1795, dos años después de su aparición, se postuló que el autor anónimo tomó como modelo para su obra la novela inglesa Cecilia, escrita por Frances Burney y publicada en $1782^{49}$. El tiempo de ferias comienza con una introducción de ocho páginas titulada «A los jovenes», en la que el narrador pone de manifiesto la finalidad didáctica de su obra:

Es menester que un libro divierta, agrade y recree, pero sobre todo es necesario que instruya, que enseñe y que corrija. [...] Procuro oponer siempre en esta obra el vicio a la virtud. Yo veo que las mas veces á pesar de todos los obstáculos,

46 Cerdonio, El Ropavejero, pág. 2.

47 Anónimo, Mis vagatelas, pág. 8.

48 Por ejemplo, en la página ocho de Mis vagatelas el narrador se refiere a los personajes Narciso, Florita y Clarita, que se sustituyen, respectivamente, por Antonio, Casilda y Antonia en la página dos de $E l$ Ropavejero. Además, los capítulos dos, tres y cuatro de Mis vagatelas que se titulan «Plazuela de la Cebada», «Las Almonedas, las Prenderias y los muebles viejos», y «Las dos Viudas. Cuento moral», se suplantan respectivamente en El Ropavejero por «Centro de la Feria», «Muebles inútiles», y «Cuento moral».

49 Citado en una nota al pie en PeÑas Ruz, «Márgenes del costumbrismo», pág. 165. Semanario de Salamanca, 12 de diciembre de 1795, págs. 257-260. 
la virtud triunfa del vicio, y que éste al fin recibe su digno castigo. He querido manifestar esta verdad en mi Novela, y hacer ver que solo la virtud puede conducirnos á la felicidad ${ }^{50}$.

Esta introducción «A los jovenes» no se reprodujo en El Ropavejero que, como ya se ha dicho, empieza con una nueva «Advertencia a quien leyere» de cuatro páginas. Solo a partir del capítulo doce de El Ropavejero se inicia la reproducción de El tiempo de ferias. En el primer capítulo del texto de 1793, el narrador presenta al protagonista, Jacinto, haciendo referencia a la educación moral que le dio su padre, Don Simon, un virtuoso hombre de bien que tuvo una carrera militar distinguida:

Don Simon dió á su hijo un Preceptor, éste le enseñó quanto puede contribuir á formar el espíritu y el corazon. Tuvo conocimiento de las ciencias y artes nobles, sabia bastante para poder pasar por un hombre de talento, y hacer su conversacion agradable y útil ${ }^{51}$.

Este párrafo se reprodujo en el capítulo doce de El Ropavejero, ahora bajo el título de «Cuento crítico.» La única diferencia que se observa es que el nombre del padre del protagonista, Don Simon, se suplanta por Don Lesmes. Después de hablar de la vida del padre de Jacinto en el prólogo de El tiempo de ferias, apunta el narrador: «Pero yo no pretendo escribir la Historia de Don Simon, es la de Jacinto su hijo ${ }^{52}$.» En el párrafo correspondiente a El Ropavejero, puede leerse: «Pero yo no pretendo escribir la Historia de Don Lesmes, sino de la de Leandro su hijo ${ }^{53}$.» Vemos con ello que el nombre Jacinto, protagonista de $E l$ tiempo de ferias, se sustituye por Leandro en El Ropavejero, observándose también una muy ligera alteración sintáctica.

Cabe subrayar que las diferencias entre los títulos de los capítulos de $E l$ tiempo de ferias y los correspondientes a El Ropavejero son más notables que las alteraciones en los once primeros capítulos del texto de Desiderio Cerdonio que reproducen Mis vagatelas. Por ejemplo, el capítulo quince de El tiempo de ferias se titula «El gabinete y la joven Lectora. Principio de una aventura interesante», y el capítulo pertinente a El Ropavejero tiene como título "Aventura amorosa.» No obstante, estos capítulos retratan a una joven virtuosa de la que se enamora Jacinto/Leandro, y a través de una comparación de las descripciones de esta jo-

\footnotetext{
50 Anónimo, El tiempo de ferias, págs. 3-6.

51 Anónimo, El tiempo de ferias, pág. 12.

52 Anónimo, El tiempo de ferias, pág. 12.

53 Cerdonio, El Ropavejero, pág. 52.
} 
ven en El tiempo de ferias y El Ropavejero, puede constatarse una reproducción casi absoluta. Describiéndola en El tiempo de ferias, anota el narrador que:

Las gracias habian animado esta bella figura, la modestia, el pudor, las demás virtudes, habian perfeccionado la obra. Todo habia contribuido á hacer de Rita (este es el nombre de la dama) una muger perfecta, una criatura excelente ${ }^{54}$.

En el párrafo correspondiente a El Ropavejero, aparte del cambio de nombre, la descripción de la joven es idéntica:

\section{EL TIEMPO}

\section{DE FERIAS, \\ ó}

TACINTO

EN MADRID.

$M A D R I D$

EN LA IMPRENTA DE RAMON RUIZ.

AÑ

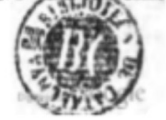

Las gracias habian animado esta bella figura, la modestia, el pudor, las demas virtudes, habian perfeccionado la obra. Todo habia contribuido á hacer de Celia (este es el nombre de la dama) una muger perfecta, una criatura excelente ${ }^{55}$.

54 Anónimo, El tiempo de ferias, pág. 51.

55 Cerdonio, El Ropavejero, pág. 79. 
Todos los ejemplos citados en esta sección iluminan las mínimas alteraciones que se llevaron a cabo entre la publicación de Mis vagatelas y El tiempo de ferias en 1791 y 1793, respectivamente, y su reproducción por El Ropavejero en 1796. Se ha demostrado que la inclusión de un prólogo nuevo en El Ropavejero representa la única diferencia notable entre este texto, Mis vagatelas y El tiempo de ferias. Hicimos mención más arriba a la segunda edición de El Ropavejero, que se publicó en 1834 en Barcelona. El Eco del Comercio del 25 de mayo de 1834 dio constancia de su reimpresión, figurando El Ropavejero en la sección titulada «Libros»: «El Ropavejero literario, en las ferias de Madrid: obra tan útil como las más, y tan inocente como pocas. Véndese en Barcelona en la librería de Solá, en Madrid en la de Jordán, y en Valencia en la de Cabrerizo, a 4 rs. ${ }^{56}{ }^{\text {» }}$

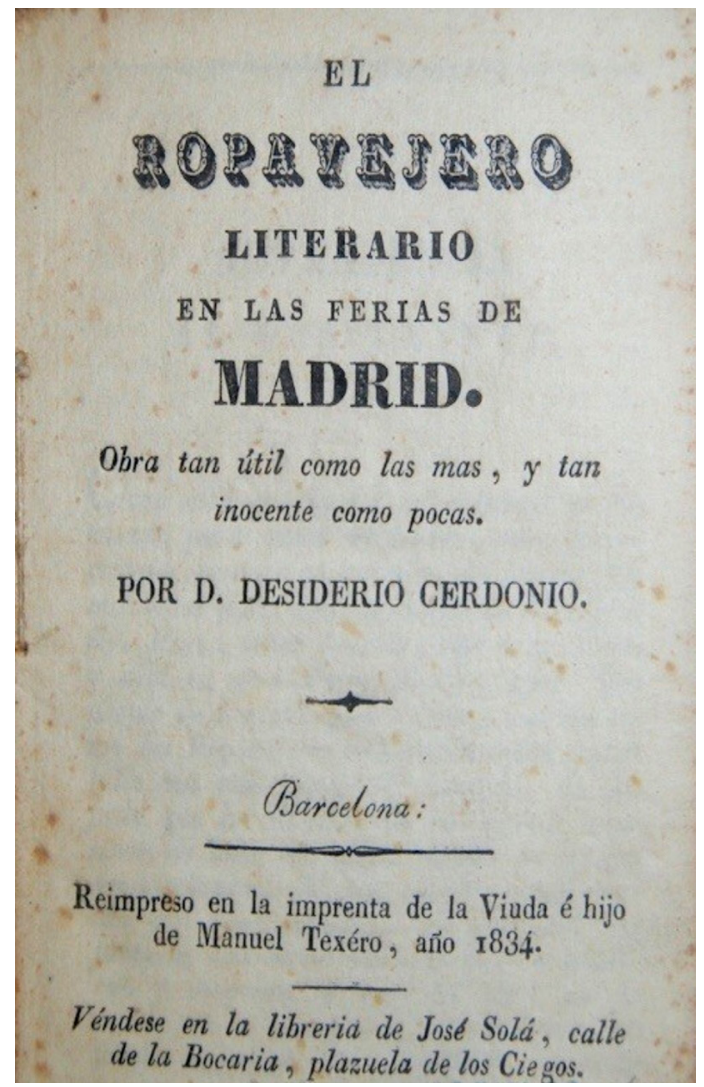

56 El Eco del Comercio, 25 de mayo de 1834, pág. 4. 
La tabla incluida más abajo incluye los títulos y las páginas de todos los capítulos de las dos ediciones de El Ropavejero. Como ya se ha demostrado, la edición de 1796 reproduce Mis vagatelas y El tiempo de ferias con ligeras alteraciones y un prólogo nuevo, constando en total de treinta y seis capítulos. No obstante, lo que destaca en la tabla es que la nueva edición de El Ropavejero contiene solo treinta y uno de los treinta y seis capítulos que conformaron la primera edición en 1796, suprimiendo los cinco capítulos indicados en rojo en la tabla. Concretamente, omite cuatro de los once capítulos de Mis vagatelas reimpresos en El Ropavejero en 1796 bajo los títulos: «Centro de la feria», «Cuento moral», «Pepito, cuento particular», $\mathrm{y}$ «Varias observaciones». Además, se incluyen en la edición de 1834 todos los capítulos de El tiempo de ferias que se reimprimieron en El Ropavejero de 1796, salvo el primero, que se titula «Cuento crítico». Esto supone que la edición de 1834 suprime el último capítulo de Mis vagatelas y el primero de El tiempo de ferias, reproducidos en los capítulos once y doce en la edición de 1796. La omisión de estos dos capítulos consecutivos, junto a los otros tres citados, podría haber obedecido a una estrategia comercial, en el sentido de acortar y renovar el texto de 1796, o quizá para ocultar su semejanza con Mis vagatelas y El tiempo de ferias. A pesar de estas omisiones, en la reimpresión de 1834 de El Ropavejero los capítulos mantienen los mismos títulos que en la primera edición. La tabla que hemos realizado muestra que la primera edición es una obra de ciento cuarenta y nueve páginas, pero la segunda se ha reducido a noventa y seis. Esta reducción se debe a que la reimpresión omite cinco capítulos, pero también a que utiliza un tipo de letra más pequeño y contiene más líneas por página que la primera edición. En concreto, la mayoría de las páginas de la edición de 1796 contienen veintiséis líneas, frente a las treinta de la segunda edición.

\begin{tabular}{|c|c|c|c|c|}
\hline \multicolumn{5}{|c|}{$\begin{array}{l}\text { Títulos y páginas de los capítulos de las dos ediciones de } \\
\text { El Ropavejero literario, en las ferias de Madrid }\end{array}$} \\
\hline Capítulos & $\begin{array}{l}\text { El Ropavejero literario, } \\
\text { en las ferias de Madrid, } \\
\text { Madrid, Imprenta de } \\
\text { Villalpando, } 1796,8^{\circ}\end{array}$ & Páginas & $\begin{array}{l}\text { El Ropavejero literario, en las } \\
\text { ferias de Madrid, Barcelona, } \\
\text { Reimpreso en la imprenta de la } \\
\text { Viuda e hijo de Manuel Texéro, } \\
1834,8^{\circ}\end{array}$ & Páginas \\
\hline Prólogo & $\begin{array}{l}\text { ADVERTENCIA AL QUE } \\
\text { LEYERE }\end{array}$ & [4 págs.] & $\begin{array}{l}\text { ADVERTENCIA AL QUE LEYERE [todo el } \\
\text { texto del prólogo está en cursiva] }\end{array}$ & [4 págs.] \\
\hline Capítulo 1 & $\begin{array}{l}\text { Particularidades de las } \\
\text { Ferias }\end{array}$ & $1-7$ & PARTICULARIDAdES dE LAS Ferias & $5-9$ \\
\hline Capítulo 2 & Centro de la Feria & $7-11$ & MUEBLES INÚTILES & $9-14$ \\
\hline
\end{tabular}


Títulos y páginas de los capítulos de las dos ediciones de

El Ropavejero literario, en las ferias de Madrid

\begin{tabular}{|c|c|c|c|c|}
\hline Capítulo 3 & Muebles inútiles & $11-17$ & LITERATURA RANCIA & $15-17$ \\
\hline Capítulo 4 & Cuento moral & $17-23$ & MUEBLES PARA NIÑOS & $17-20$ \\
\hline Capítulo 5 & Literatura Rancia & $23-26$ & LA TIENDA DE LA TIA JUANA & $20-24$ \\
\hline Capítulo 6 & Muebles para niños & $26-30$ & PASEO DE LA PLAZUELA DE LA CEBADA & $24-26$ \\
\hline Capítulo 7 & La tienda de la tia Juana & $30-36$ & REFLECSIONES PARTICULARES & $26-29$ \\
\hline Capítulo 8 & Pepito, cuento particular & $36-40$ & EL AMIGO FINGIDO & $29-32$ \\
\hline Capítulo 9 & $\begin{array}{l}\text { Paseo de la plazuela de la } \\
\text { Cebada }\end{array}$ & $41-43$ & TODO CANSA & $33-34$ \\
\hline Capítulo 10 & Reflexîones particulares & $43-47$ & NUEVAS DIVERSIONES & $34-36$ \\
\hline Capítulo 11 & Varias observaciones & $48-51$ & CÓMO SE HA DE EVITAR EL MAL & $37-38$ \\
\hline Capítulo 12 & Cuento crítico & $51-54$ & [Sin título] & $39-41$ \\
\hline Capítulo 13 & El Amigo fingido & $54-58$ & PROSIGUE LO MISMO & $41-42$ \\
\hline Capítulo 14 & Todo cansa & $59-61$ & NUEVAS AVENTURAS & $43-44$ \\
\hline Capítulo 15 & Nuevas diversiones & $61-63$ & CARÁCTER DE LEANDRO & $44-46$ \\
\hline Capítulo 16 & Como se ha de evitar el mal & $64-66$ & CASUALIDAD FELIZ & $46-47$ \\
\hline Capítulo 17 & [Sin título] & $66-69$ & AVENTURA AMOROSA & $47-50$ \\
\hline Capítulo 18 & Prosigue lo mismo & $69-72$ & PROSIGUE LA AVENTURA & $50-54$ \\
\hline Capítulo 19 & Nuevas aventuras & $72-74$ & LA CENA Y LA MEDIANOCHE & $55-56$ \\
\hline Capítulo 20 & Carácter de Leandro & $74-76$ & EFECTOS DEL AMOR & $57-60$ \\
\hline Capítulo 21 & Casualidad feliz & $76-78$ & LA MADRUGADA & $60-62$ \\
\hline Capítulo 22 & Aventura amorosa & $78-82$ & EL VIRLOCHO INGLÉS & $62-64$ \\
\hline Capítulo 23 & Prosigue la aventura & $82-88$ & PROSIGUE EL PASEO & $65-66$ \\
\hline Capítulo 24 & La cena, y la media noche & $88-91$ & EL ALMUERZO & $66-73$ \\
\hline Capítulo 25 & Efectos del Amor & $91-95$ & EL BAILE Y LA MÚSICA & $73-75$ \\
\hline Capítulo 26 & La madrugada & $95-98$ & LA ÓPERA & $75-79$ \\
\hline Capítulo 27 & El Virlocho Inglés & $98-101$ & CONVERSACION & $79-83$ \\
\hline Capítulo 28 & Prosigue el paseo & $101-104$ & LA MUGER DE JUICIO & $83-86$ \\
\hline Capítulo 29 & El Almuerzo & $104-112$ & LA VIRTUD TRIUNFA & $87-90$ \\
\hline Capítulo 30 & El bayle y la música & $113-115$ & ¿¿SE OCULTARÁ LA MALDAD? & $90-92$ \\
\hline Capítulo 31 & La Opera & $116-121$ & LA ESPOSA Á MI GUSTO & $93-96$ \\
\hline Capítulo 32 & Conversacion & $122-127$ & & \\
\hline Capítulo 33 & La muger de juicio & $127-131$ & & \\
\hline Capítulo 34 & La virtud triunfa & $131-138$ & & \\
\hline Capítulo 35 & ¿Se ocultará la maldad? & $138-143$ & & \\
\hline Capítulo 36 & La Esposa á mi gusto & $143-149$ & & \\
\hline
\end{tabular}

Un análisis de la reimpresión de 1834 revela que se llevaron a cabo más cambios entre la primera y la segunda edición. En primer lugar, se observan ligeras alteraciones ortográficas en todos los capítulos de acuerdo con los nue- 
vos usos ortográficos, así por ejemplo en el primer capítulo de la edición de 1796 cuando el narrador habla de las ferias y observa: «Esta conmocion no reyna solo en Madrid, se extiende á las Provincias mas remotas, y alcanza hasta la extremidad del globo ${ }^{57}$.» En el párrafo correspondiente a la nueva edición anota el narrador: «Esta conmocion no reina solo en Madrid, se estiende á las Provincias mas remotas, y alcanza hasta la estremidad del globo ${ }^{58}$.» Además de estas pequeñas modificaciones, cabe señalar que en algunos de los capítulos de la nueva edición se llevaron a cabo alteraciones de mayor calado por lo que respecta al léxico y al contenido. Notablemente, en el segundo capítulo de la edición de 1796 el narrador se refiere a los pisaverdes, presentándolos como tipos superficiales: «Un Pisaverde afectado, lleno de dixes y olores, entra seguido de una tropa de monos é ignorantes como él haciendo mil estudiadas contorsiones, meneos, corcobos y gestos $[\ldots]^{59}$.» En el mismo párrafo de la reimpresión de 1834 afirma el narrador: «Un lechuguino afectado, lleno de dijes y olores, entra seguido de una caterva de monos é ignorantes como él haciendo mil estudiados contorsiones, meneos, corcobos y gestos $[\ldots]^{60}$.» Aparte del reemplazo de «tropa» por «caterva», llama la atención aquí la sustitución del tipo social «pisaverde», variante del petimetre, por «lechuguino». Este cambio se debe con toda probabilidad a la contemporaneidad de este último término en los años treinta del siglo XIX, y la adscripción de los petimetres y los pisaverdes a las últimas décadas del XVIII. En efecto, en repetidas ocasiones en la reimpresión se observa la sustitución de los términos «petimetre» y «pisaverde», notablemente en el capítulo titulado «Literatura rancia», que representa el quinto capítulo de la edición de 1796, y el tercero de la de 1834. Refiriéndose a los tipos sociales de las clases altas, dice el narrador de la primera edición: «Los petrimetes (sic) de la literatura, pues tambien en la literatura hay petimetres, y los Eruditos á la Violeta, dos nombres quasi sinonimos $[\ldots]^{61}$.» En la reimpresión se lee: «Los lechuguinos de la literatura, pues tambien en la literatura los hay, y los fanfarrones, dos nombres cuasi sinonimos $[\ldots]^{62}$.» Además de la sustitución del tipo social «petimetre» por el más contemporáneo «lechuguino», sobresale el reemplazo de «Eruditos a la Violeta» — término utilizado inicialmente por José de Cadalso en su obra epónima de 1772 para referirse a los petimetres— por

57 Cerdonio, El Ropavejero, primera edición, pág. 4.

58 Desidero Cerdonio, El Ropavejero literario, en las ferias de Madrid. Obra tan util como las mas, y tan inocente como pocas. Por D. Desiderio Cerdonio, Barcelona, Reimpreso en la imprenta de la Viuda é hijo de Manuel Texéro, 1834, 8, 96 págs, [4]; pág. 7.

59 Cerdonio, El Ropavejero, primera edición, pág. 13.

60 Cerdonio, El Ropavejero, segunda edición, pág. 11.

${ }_{61}$ Cerdonio, El Ropavejero, primera edición, pág. 25.

62 Cerdonio, El Ropavejero, segunda edición, pág. 16. 
«fanfarrones», una palabra de sentido más general para caracterizar a tipos sociales exagerados. Es probable que tales cambios en la reimpresión de 1834 representaran una estrategia utilizada por el editor en Barcelona para renovar el texto y adaptarlo al entorno social de los años treinta del siglo XIX, un período durante el cual términos como «lechuguino» aparecían con bastante frecuencia, notablemente en los artículos de costumbres de Mariano José de Larra, y que, por lo tanto, sonaban más de su tiempo a los lectores de estos años que las voces «petimetre» $\mathrm{y}$ «pisaverde».

Además de estos cambios en el léxico, se evidencia una expresión más sumaria en algunos de los párrafos de los capítulos de la nueva edición. Para dar un ejemplo, en el sexto capítulo de la edición de 1796 habla el narrador de los juguetes que podían adquirirse en las covachuelas bajo las gradas de San Felipe:

Sin embargo, la mayor parte de estos jueguezuelos nos vienen de Alemania, é importan algunas sumas considerables: ved aquí un ramo de comercio que aunque pequeño á primera vista, no dexa de ser en sí algo interesante. La Nacion ganaria en que estos y otros muchos objetos de luxo ó entretenimiento se fabricaran en ella. Sea esto dicho entre parentesis ${ }^{63}$.

Mientras que en el capítulo correspondiente a la reimpresión de 1834, apunta el narrador:

Sin embargo la mayor parte de estos jueguezuelos antes nos venían de Alemania é importaban sumas considerables, pero aora es muy aventajado á la Nacion, el que por su industria estos y otros muchos objetos de lujo y entretenimiento se fabriquen en ella ${ }^{64}$.

Una comparación entre estos dos párrafos demuestra que en la nueva edición se modifican los tiempos verbales, y el narrador utiliza ahora el pretérito imperfecto para hablar de cómo la importación de juguetes desde los talleres alemanes impactaba entonces de manera negativa en la economía española, lo cual indica un punto de vista retrospectivo. Además, en la reimpresión el narrador reduce la argumentación sin perder del todo la finalidad de promover una moralidad económica de acuerdo al pensamiento ilustrado, resaltando lo beneficioso de fabricar juguetes en las industrias nacionales. Por todo ello,

63 Cerdonio, El Ropavejero, primera edición, págs. 27-28.

64 Cerdonio, El Ropavejero, segunda edición, pág. 18. 
teniendo en cuenta las diferencias que se observan entre las dos ediciones de este texto, ¿cómo se explica la recuperación del texto de Desiderio Cerdonio, publicado por vez primera hacía ya treinta y ocho años? Posiblemente porque El Ropavejero era una obra asimilable al costumbrismo de los años treinta del siglo XIX, especialmente a los artículos de costumbres de Mariano José de Larra y Mesonero Romanos. Por lo tanto, es posible que el editor de la segunda edición creyese que una reimpresión de El Ropavejero podría interesar todavía a los lectores que se habían familiarizado con la renovada literatura de costumbres.

Teniendo en cuenta los paralelismos y las diferencias que se observan entre Mis vagatelas, El tiempo de ferias, y las dos ediciones de El Ropavejero, propondremos a continuación los diferentes escenarios que explican la reproducción de los dos textos anónimos de 1791 y 1793 por El Ropavejero en 1796. Para ello, fijaremos nuestra atención en los anuncios de las tres obras que vieron la luz en el Diario de Madrid y la Gaceta de Madrid que, como ya se ha dicho, nos ofrecen la oportunidad de examinar su venta en las librerías madrileñas, con el objetivo de determinar su autoría ${ }^{65}$.

Los anuncios de la serie en la prensa madrileña: mecanismos de identificación autoral

Como ya sabemos, los periódicos contribuían a la venta de los libros a través de los anuncios que aparecían regularmente en las secciones de anuncios de literatura, sobre todo en la Gaceta de Madrid y el Diario de Madrid, las dos publicaciones más centradas en la publicidad de libros en las décadas finales del siglo XVIII. En palabras de Cavaillon Giomi, bajo el reinado de Carlos IV, «Avec une représentation de 74,92\% de titres annoncés à eux deux, la Gaceta de Madrid et le Diario de Madrid furent, sans surprise, les journaux les plus prisés en matière de diffusion d'imprimés ${ }^{66}$.» Por lo que respecta al $D M^{67}$, las obras de reciente aparición solían anunciarse en la sección titulada Noticias particulares de Madrid, situada en las dos últimas páginas de este periódico diario de cuatro páginas, mientras que en la $G M$ los anuncios de libros se encontraban típicamente bajo la rúbrica Libros.

65 No hemos incluido en el gráfico la segunda edición de El Ropavejero, puesto que escapa al período en que coincidió la venta de Mis vagatelas, El tiempo de ferias, y la primera edición del texto de Desiderio Cerdonio.

66 Cavaillon Giomi, L'édition sous Charles IV, pág. 136.

${ }^{67}$ De aquí en adelante utilizaré las abreviaturas $D M$ y $G M$ para referirme, respectivamente, al Diario de Madrid y a la Gaceta de Madrid. 


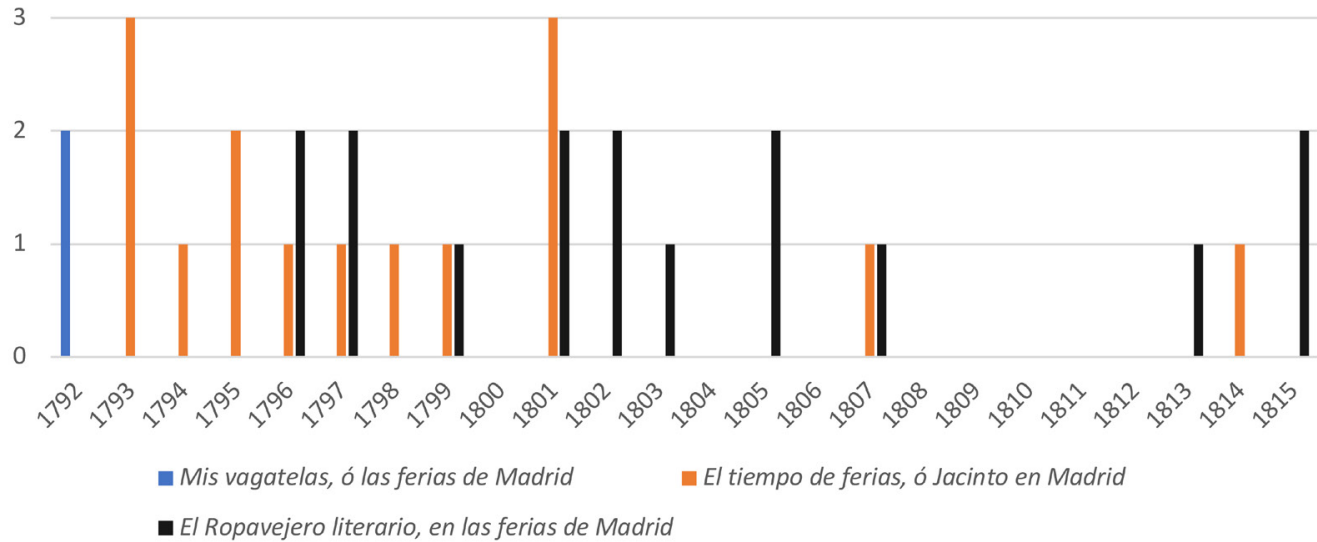

Con respecto a los anuncios de Mis vagatelas, El tiempo de ferias y la primera edición de El Ropavejero, el gráfico indica que aparecieron en diferentes números del $D M$ y de la $G M$ en contigüidad a su lanzamiento en 1791, 1793 y 1796, pero muestra también que solo dos de las tres obras se volvieron a anunciar en los años que siguieron su aparición. Como veremos después, se evidencia la frecuente y repetida publicación de estos anuncios en los números de la $G M$ y del $D M$ publicados en los días inmediatos a la celebración de las ferias de Madrid en la segunda quincena de septiembre, sin duda por una motivación comercial. Como apunta Cavaillon Giomi:

[La] pratique qui consistait à réitérer plusieurs fois l'annonce d'un même livre permettait aussi aux libraires de se rappeler au bon souvenir des lecteurs à certaines époques du calendrier propices à la vente d'une œuvre en fonction de son thème ${ }^{68}$.

Por lo tanto, resulta probable que los libreros quisieron anunciar sus ejemplares disponibles de estas obras en los números de la prensa madrileña publicados durante las ferias para aprovechar el tirón de estas para con el tema central de las mismas. Aunque, como explica Peñas Ruiz, estas obras represen-

68 CavallLon Giomi, L'édition sous Charles IV, pág. 140. 
tan «una literatura de circunstancias, donde las ferias sólo son descritas incidentalmente y se utilizan como reclamo publicitario ${ }^{69}$.» Además del problema textual planteado por la reproducción de Mis vagatelas y El tiempo de ferias por El Ropavejero literario, todo ello supuso también un problema comercial, que puede iluminarse si consideramos los anuncios de los tres textos aparecidos en la prensa durante el período 1792-1815. En primer lugar, como revela el gráfico, un año después de su lanzamiento Mis vagatelas se anunció dos veces ${ }^{70}$, primero en el $D M$ del 22 de septiembre de 1792, y también seis días más tarde en la GM. Ambos periódicos informaban que la obra se vendía «en las librerías de Escribano, calle de las Carretas, en la de Arribas carrera de S. Gerónimo, en el puesto del Diario frente a Sto. Tomás, y en el de López en la plazuela de Sto. Domingo $^{71}$.» No se volvió a anunciar, lo cual sugiere que se vendieron todos los ejemplares de su tirada.

Un año después, en 1793, se publicó El tiempo de ferias que, como se puede ver en el gráfico, se anunció al menos una vez durante todos los años que van entre 1793 y 1799, para luego volverse a publicitar ocasionalmente hasta 1814. La obra se podía comprar inicialmente en una única librería y en dos puestos, como manifiesta el número de la GM correspondiente al 27 de septiembre de 1793, en que se anunció por vez primera:

El tiempo de ferias ó Jacinto en Madrid. [...] Se hallará á 4 rs. en la Librería de Escribano, calle de las Carretas; en los puestos del Diario, frente á Sto. Tomas; y de Lopez, plazuela de Sto. Domingo ${ }^{72}$.

Pero un año después, pasó a venderse ya solamente en la librería de Escribano, como manifiesta el $D M$ del 6 de octubre de 1794: «El tiempo de Ferias, ó Jacinto en Madrid, [...] se hallará en la Libreria de Escribano, calle de las Carretas, y puede ir en carta $^{73}$.» En los años siguientes hasta octubre de 1814, continuó vendiéndose exclusivamente en dicha librería ${ }^{74}$.

69 Peñas Ruiz, «Márgenes del costumbrismo», pág. 165.

70 En el año de su lanzamiento, 1791, no se anunció en la prensa, pero sí se incluyó en el Índice literario, ó biblioteca anual para utilidad de los literatos y curiosos, donde se informaba que Mis vagatelas se vendía a 2 reales en las librerías de Escribano y de Arribas. vIII, pág. 37.

71 DM, 22 de septiembre de 1792, pág. 1116; GM, 28 de septiembre de 1792, pág. 680.

$72 G M, 27$ de septiembre de 1793, pág. 988.

73 DM, 6 de octubre de 1794, pág. 1141.

$74 D M, 24$ de octubre de 1814, pág. 455. En la ya citada reseña de El tiempo de ferias publicada en el número del Semanario de Salamanca correspondiente al 12 de diciembre de 1795, se indicaba que la novela podía adquirirse en Salamanca en la librería de Alegría. Véase Semanario de Salamanca, 12 de diciembre de 1795, págs. 257-260. 
Por lo que respecta a El Ropavejero, el gráfico revela que se anunció por vez primera en 1796, concretamente en el $D M$ del 22 de septiembre. Se informaba que la obra:

Se vende á 4rs: a la rustica, en la libreria de Esparza Puerta del Sol, en la de Hurtado calle de las Carretas, en la de la Viuda de Fernandez frente á S. Felipe el Real, en el puesto de frente á S. Luis, en los del Diario plazuela de Sto. Domingo, calle de Toledo y frente á Sto. Tomas ${ }^{75}$.

La publicidad de El Ropavejero en los periódicos madrileños no coincidió, por tanto, con la de Mis vagatelas, puesto que esta última obra solo se anunció en la prensa dos veces, en septiembre de 1792. No obstante, el gráfico muestra que aparecieron a la vez anuncios de El Ropavejero y El tiempo de ferias en 1796, 1797, 1799, 1801 y 1807. El Ropavejero podía adquirirse inicialmente en las librerías de Esparza, de Hurtado, y de la Viuda de Fernández, además de en cuatro puestos, mientras El tiempo de ferias, durante el mismo período, continuaba a la venta solo en la librería de Escribano ${ }^{76}$.

Sin embargo, a la altura de noviembre de 1796, dos meses después del lanzamiento de $E l$ Ropavejero, el $D M$ informaba que ya únicamente se vendía en la librería de Esparza: «El ropavejero Literario en la Corte de Madrid [...] á 4 rs. a la rustica [...] en la Libreria de Esparza Puerta del Sol ${ }^{77}$.» Este anuncio subraya que a partir de noviembre de 1796, El tiempo de ferias y El Ropavejero se vendían simultáneamente en las librerías de Escribano y en la de Esparza, respectivamente. Como se ve por el gráfico, esta situación se repitió en 1797, 1799, 1801 y 1807, pero en 1799 El Ropavejero volvió a venderse tanto en la librería de Esparza como en la de Fernández, como informaba la GM del 11 de octubre de 1799:

El Ropavejero literario en las ferias de Madrid, obra útil é inocente, dada á luz por D. Desiderio Cerdonio: un tomo en $8^{\circ}$. Se hallará en las librerías de Esparza, puerta del Sol; y de Fernandez, frente á las gradas de S. Felipe ${ }^{78}$.

Dos años después, en 1801, el texto de Desiderio Cerdonio pasó a venderse en las librerías de Esparza y Montero, como manifiesta el DM del 24 de septiembre:

$75 \quad D M, 22$ de septiembre de 1796, pág. 1087.

76 DM, 27 de septiembre de 1796, pág. 1106.

77 DM, 2 de noviembre de 1796, pág. 1249.

$78 G M, 11$ de octubre de 1799, pág. 890. 
El Ropavejero literario en las ferias de Madrid [...]. Se hallará á 4 rs. á la rústica en las librerías de Esparza, puerta del Sol; y de Montero, calle de la Concepcion, casas de Sto. Tomás, y puede ir en carta $^{79}$.

Así, mientras El tiempo de ferias solamente seguía vendiéndose en la librería de Escribano ${ }^{80}$, El Ropavejero se podía comprar en las librerías de Esparza, de Fernández, y de Montero. El gráfico revela que El tiempo de ferias no se anunció en la prensa entre 1801 y 1807, mientras que El Ropavejero continuaba vendiéndose en las librerías de Esparza y Montero en $1805^{81}$. No obstante la falta de anuncios de El tiempo de ferias en la prensa después de 1801, este texto se volvió a publicitar simultáneamente en 1807 con El Ropavejero. Así, por lo que se refiere a El Ropavejero, el $D M$ del 29 de septiembre de 1807 informaba que el libro todavía podía adquirirse en las tiendas de Esparza y Montero ${ }^{82}$; y en la $G M$ de ese mismo día, apareció un anuncio de El tiempo de ferias, la primera vez en casi siete años:

El Tiempo de ferias, ó Jacinto en Madrid: es una pintura de quanto pasa en Madrid en tiempo de ferias, en una novela moral, dedicada á los jóvenes. Véndese en la librería de Escribano, calle de las Carretas, á 4 rs. Puede ir en carta ${ }^{83}$.

Este anuncio demuestra que aunque El tiempo de ferias no apareció en la prensa entre 1801 y 1807, todavía se encontraba a la venta en la librería de Escribano en septiembre de 1807, catorce años después de su lanzamiento. Como se ve por el gráfico, las dos obras no se anunciaron entre 1808 y 1812, probablemente debido al desfavorable clima económico provocado por los vaivenes de la Guerra de la Independencia. El tiempo de ferias se publicitó por última vez en 1814, mientras que El Ropavejero seguía en venta todavía en 1815, pero ahora ya exclusivamente en la librería de Montero ${ }^{84}$.

Todos estos anuncios de prensa indican que después de la salida de $E l$ Ropavejero en septiembre de 1796, se anunciaba en paralelo a El tiempo de ferias, no obstante su práctica identidad textual. ¿Cómo, entonces, se explica la reproducción de Mis vagatelas y El tiempo de ferias por El Ropavejero? ¿Quién fue el autor de esta serie de obras? Hace unos años propuso Francisco Aguilar Piñal:

\footnotetext{
$79 \quad D M, 24$ de septiembre de 1801, pág. 1095.

$80 \quad D M, 3$ de octubre de 1801, págs. 1129-1130.

$81 \quad D M, 26$ de septiembre de 1805, pág. 356.

$82 \quad D M, 29$ de septiembre de 1807, pág. 384.

$83 \quad G M, 29$ de septiembre de 1807, pág. 1012.

84 GM, 23 de septiembre de 1815, pág. 1106.
} 
«Aunque carezco de pruebas documentales (y las he buscado con insistencia), los indicios textuales me llevan a presentar a Cándido María Trigueros como el autor de las tres obritas ${ }^{85}$.» Relaciona Mis vagatelas con la obra de Trigueros titulada Mis pasatiempos, publicada en 1804 pero escrita unos años antes, viendo paralelismos entre los títulos y argumentando también que el tono didáctico y moralizante de esta serie en torno a las ferias corresponde al de Mis pasatiempos y, más generalmente, a los valores patrocinados por Trigueros. Sin embargo, a la luz de la falta de documentación para corroborar la aseveración de Aguilar Piñal, no podemos decir con certeza que esta serie de obras salió de la pluma de Trigueros, y puesto que no se hallan los tres textos entre las licencias de impresión del Archivo Histórico Nacional que he consultado - a pesar de que en la portada de la primera obra de la serie se incluyen las palabras «con licencia»—, todavía no es posible poner nombre a este autor oculto, lo cual me lleva a proponer otras posibilidades para explicar la conexión entre estas tres obras basadas en su venta en el mercado del libro madrileño, tal como se observa en los anuncios de prensa que acabamos de examinar.

En primer lugar, podría tratarse de un caso de plagio, en el cual Desiderio Cerdonio reprodujera los textos anónimos ajenos de Mis vagatelas y El tiempo de ferias, añadiendo algunos pocos cambios menores que camuflasen el plagio. Se produciría así un fraude al lector que había comprado y leído los dos textos previos, y que podía adquirir este tercero, y también un evidente perjuicio económico al librero Escribano, que continuaba vendiendo El tiempo de ferias, y que había vendido anteriormente Mis vagatelas. Sin embargo, es más probable que Mis vagatelas y El tiempo de ferias salieran de la pluma de un mismo autor. En este caso, es de presumir que todos los ejemplares de Mis vagatelas se agotaran, y que el autor escribiera una nueva obra, El tiempo de ferias, presentándose otra vez anónimamente. Según esta hipótesis, tres años después, en 1796, este mismo autor reprodujo ambos textos como una sola obra, El Ropavejero y, mientras El tiempo de ferias continuaba vendiéndose en la librería de Escribano, la nueva obra que incorporaba las dos anteriores se vendía inicialmente en otras tres librerías y cuatro puestos ${ }^{86}$, antes de pasar a venderse en las librerías de Esparza, Fernández y Montero, y finalmente solamente en la de Montero. La venta paralela de El Ropavejero en estas tres librerías debió ocasionar un daño comercial a Escribano, pues a partir del lanzamiento de El Ropavejero en septiembre de

85 Francisco Aguilar Piñal, «Mis vagatelas, ¿̨de Trigueros?», en Joaquín Álvarez Barrientos y Jerónimo Herrera Navarro (eds.), Para Emilio Palacios Fernández. 26 estudios sobre el siglo Xvil español, Madrid, Fundación Universitaria Española, Real Sociedad Bascongada de los Amigos del País, 2011, págs. 327-349; pág. 346.

86 DM, 22 de septiembre de 1796, pág. 1087. 
1796 los ejemplares de El tiempo de ferias resultaban sin lugar a dudas menos atractivos, especialmente si tenemos en cuenta que ambos impresos costaban exactamente lo mismo, 4 reales $^{87}$. Por todo ello, resulta probable que Mis vagatelas, El tiempo de ferias, y El Ropavejero hubieran sido impresos a costa de un mismo autor, que pretendería así obtener tres veces un beneficio económico, vendiendo los dos textos originales y El Ropavejero a libreros distintos. Debido a que el autor se presentó anónimamente tanto en Mis vagatelas como en El tiempo de ferias, la ocultación de la identidad en El Ropavejero, que combina los dos textos previos con ligeros cambios, ya no funcionaba como estrategia comercial, y se vio obligado a inventar una máscara reveladora, Desiderio Cerdonio ${ }^{88}$, pseudónimo de difícil interpretación que servía para seguir ocultando la identidad del autor anónimo de Mis vagatelas y El tiempo de ferias y, en consecuencia, permitirle el reproducir sus propias obras de 1791 y 1793 con mínimos cambios.

El propio título de la obra publicada en 1796 parece sostener también la hipótesis de que el autor de Mis vagatelas y El tiempo de ferias refundiera sus trabajos previos en 1796, pues la imagen de El Ropavejero evoca la idea de reutilizar algo viejo, como hacían contemporáneamente los ropavejeros que trabajaban en los barrios populares de la capital española retocando y revendiendo ropa gastada. Además, en el prólogo de El Ropavejero, el narrador parece hacer otra oscura alusión metafórica a la idea de estar reproduciendo Mis vagatelas y El tiempo de ferias. Así, refiriéndose a cómo los lectores evaluarán su obra, supuestamente nueva, apunta:

Si hace dormir, haga Vmd. cuenta que envió á la botica por un narcotico, tanto mas útil, quanto no le destruirá la salud, y puede repetir el remedio siempre que lo necesite, sin desembolsar nuevo dinero ${ }^{89}$.

Se podría argumentar que la alusión que hace al ahorro económico que ofrece la reutilización del mismo remedio farmacéutico para tratar una enfermedad médica funciona como imagen reveladora de su intencionada reproducción de los textos anónimos previos Mis vagatelas y El tiempo de ferias.

${ }_{87}$ Curiosamente, en la portada de un ejemplar digitalizado de El Ropavejero que se conserva en la biblioteca de la Universidad de Toronto, se indica que al dueño del libro, Don Gregorio de Calzada, solo le costó dos reales, pero lo debió de adquirir en la segunda década del siglo xix, como es el caso de otros libros que le pertenecieron. Véase https://archive.org/details/elropavejerolite00cerd/page/n7/mode/2up.

88 Confirma Aguilar Piñal que buscó entre la documentación del AHN para intentar descifrar el pseudónimo Desiderio Cerdonio, pero sin éxito. En su ya citado trabajo, afirma que «Lo único interesante es un sello de la Casa Real en uno de los ejemplares [de El Ropavejero] de la Biblioteca Nacional de Madrid.» Agullar Piñal, «Mis vagatelas, ¿¿de Trigueros?», pág. 342.

89 Cerdonio, El Ropavejero, «Advertencia», primera edición, página sin numerar. 


\section{Conclusiones}

A modo de conclusión, este artículo ha querido ofrecer un estudio particular de esta serie de obras en torno a las ferias de Madrid, situándola dentro de la naciente literatura costumbrista que fue surgiendo durante la época de Carlos IV, y demostrando las diferentes técnicas utilizadas por el autor de Mis vagatelas y El tiempo de ferias para ocultar su identidad y permitirse así el refundir sus dos obras previas originales en El Ropavejero literario, concretamente los pequeños cambios en el lenguaje, la omisión de la firma, y también el uso de un pseudónimo de difícil desciframiento. Frente a estas estrategias autorales y la ausencia de documentación en los archivos acerca de la impresión de los tres libros, nuestro estudio ha buscado subrayar cómo los anuncios de dichas obras aparecidos en la prensa oficial y local madrileña han servido como fuentes de gran utilidad para investigar este caso de ocultación de autoría. Pese a que estos anuncios no nos han conducido a desenmascarar al autor de esta serie, sí nos han ayudado a proponer una hipótesis que explique la conexión entre las tres obras a partir de su comercialización en diferentes librerías madrileñas en la divisoria de los siglos XVIII y XIX. Confirman que los tres textos se anunciaban principalmente, tanto en los años de su aparición, como en los siguientes, durante las semanas inmediatas a las ferias de Madrid de finales de septiembre, práctica que evidencia el deseo de los libreros de vender su remanente de ejemplares aprovechando el reclamo comercial que presentaba la celebración de las ferias y el tema central de estas tres obras.

A pesar de que no hemos profundizado aquí en el análisis de los episodios de este corpus textual, que no ha sido el objetivo de este trabajo, nuestro examen de los paralelismos y las diferencias entre las tres obras que componen esta serie ha resaltado la afición que madrileños y visitantes de provincias tenían por las ferias de Madrid. Se ha demostrado asimismo que esta feria anual le sirvió al autor desconocido de esta serie como ambiente pertinente para expresar unas posturas moralizantes, subrayando los peligros que presentaba este mercado extraordinario por lo que respecta al gasto excesivo y a la corrupción de las costumbres, e intentando así animar a sus lectores, que con toda probabilidad asistían a las ferias, a actuar de manera responsable. Finalmente, este trabajo ha incorporado a la discusión la reimpresión de El Ropavejero de 1834, publicada casi cuarenta años después de su primera edición, cuando el costumbrismo se consolidaba como género literario con los artículos de Larra y de Mesonero Romanos. Nuestro análisis de los cambios textuales que se hicieron con la publicación de la segunda edición de la obra de Desiderio Cerdonio, específicamente el acortamiento del texto, la actualización de la ortografía y la modernización de 
los términos utilizados por el narrador para referirse a determinados tipos sociales, ha destacado la semejanza entre este texto y los artículos de costumbres de estos dos máximos representantes del costumbrismo, señalando así el interés que tiene esta serie, por encima de la cuestión de la autoría, para elucidar los antecedentes dieciochescos del costumbrismo de los años treinta del siglo XIX. 